\title{
NLM's revolution in consumer health information to improve patient outcomes
}

\author{
Kathleen Cravedi* \\ U.S. National Library of Medicine, Maryland, USA
}

\begin{abstract}
Under the leadership of NLM Director Donald A.B. Lindberg M.D., the National Library of Medicine (NLM) continued to promote its services to the nation's health care professionals and scientists. With support of the U.S. Congress, it initiated new communications and outreach programs and services directed at the general public that revolutionized their access to information as well. Because effective health communication must be tailored for the audience and the situation, Lindberg supported the development of online health information tools designed to help consumers find free, comprehensive, timely, and trustworthy sources of health information that, ultimately, can improve patient outcomes. New and popular consumer-friendly websites were championed by Lindberg, including MedlinePlus, and ClincialTrials.gov, and he formed unique partnerships with national physician organizations to educate their patients about reliable sources of health information from the NLM. A new era of timely and trusted online health information for the general public began in 2006 under Lindberg's tenure culminating in the development, publication and distribution of NIH's first consumer magazine, NIH MedlinePlus, featuring the research and findings of the NIH. In his effort to improve patient outcomes, Dr. Lindberg revolutionized the Library's outreach capabilities and successfully expanded its mission to serve not only health professionals and scientists, but also consumers nationwide.
\end{abstract}

Keywords: U.S. National Library of Medicine, Donald A.B. Lindberg M.D., outreach, consumer health

\section{Introduction}

When Donald A. B. Lindberg M.D. arrived at NIH in 1984, NLM had a straightforward mission: to serve health professionals and scientists primarily through libraries. This function was expanded in 1989 with a new emphasis on serving health professionals unaffiliated with a health sciences library and/or located in remote or underserved areas of the country [1]. There was, however, no attempt yet to serve the general public. While he continued to promote NLM's services to health professionals, beginning in the early 1990s, Lindberg began to develop and support outreach and communication activities directed at the consumer. Their technical development is described in detail elsewhere in this book. See for example [2].

Today, we take this second prong of the NLM mission for granted. Here's the story of how it came to be from the personal perspective of Kathleen Cravedi M.S., who served under Dr. Lindberg as Director of the Office of Communications and Public Liaison.

\footnotetext{
${ }^{*}$ Corresponding author: Kathleen Cravedi, M.S., retired. E-mail: cravedikathleen@gmail.com.
} 


\section{Lindberg promotes NLM information services to consumers}

One of Lindberg's earliest efforts to establish a focus on public outreach was initiated in 1996 by his creation of a NLM Board of Regent's Subcommittee on Outreach and Public Information. The Subcommittee was chaired by the famous cardiovascular surgeon Dr. Michael DeBakey who, a few years earlier, had chaired the panel of the Board whose report jump started a new generation of outreach initiatives created and implemented by Dr. Lindberg and his outreach team [1]. His sister, Dr. Lois DeBakey, a scientific communications professor at Baylor College of Medicine also served on the Subcommittee and as a consultant to the NLM Board of Regents. Both DeBakeys shared Lindberg's view that the American public should have the same access to the medical literature that physicians and other health professionals used in their daily practice of medicine. Under Lindberg's dynamic leadership, they also encouraged the "Outreach" Subcommittee to recommend that the NLM drastically increase efforts to ensure that its unparalleled information resources be fully utilized by scientists and health professionals around the globe and shared with the consumers as well [3].

In June 1996, Lindberg held a press conference to launch Internet Grateful Med at the annual conference of the Friends of the National Library of Medicine at Georgetown University [4]. The event, hosted by Lindberg, featured Dr. DeBakey and Senator Bill Frist, (R-TN), a physician and surgeon, who conducted the first Internet search via Internet Grateful Med - a program for searching MEDLINE via the World Wide Web. Also speaking at the event were members of the Odone family whose true story was immortalized in the Hollywood's academy nominated film Lorenzo's Oil. The Odones, who lived six blocks from the NLM said they found a treatment for their son's terminal illness by researching the medical literature at NLM. They said, with Internet Grateful Med, all people could now have the same access to the Library's resources no matter where they lived in the world.

The DeBakeys personally marketed NLM products to the media, convincing Ann Landers to devote a column to NLM information services and getting popular medical TV shows such as ER and Chicago Hope to mention NLM's MEDLINE in more than eight episodes resulting in an explosion in the usage of NLM's online information resources. Dr. DeBakey produced a print campaign with the National Network of Libraries of Medicine (NNLM) called "Medical Questions? Medline Has Answers," and a TV public service announcement featuring DeBakey called "Good Information is the Best Medicine".

In testimony before a House Appropriations Subcommittee on Labor, HHS on April 15, 1997, Dr. DeBakey urged Congress to improve public access to health information. As a direct result of his testimony, MEDLINE became free to the public in that same year, and a fact highlighted in a 1997 bipartisan congressional press briefing sponsored by former Senator Tom Harkin, D-IA, and the late Senator Arlen Specter (R-PA). Then Vice President Al Gore, assisted by David Lipman, M.D., Director of NLM's National Center for Biotechnology Information, conducted the first free Internet search of MEDLINE via PubMed (See Photo 1). Gore noted that "free Internet access to MEDLINE might do more to reform and improve the quality of health care in the U.S. than anything in a long time". "The National Library of Medicine's debut of free Web-based searching could not be timelier", said NLM Director Lindberg, "The health care delivery landscape is changing. Citizens are increasingly turning to the Web as a source of information to improve their daily lives, including their health. So, it is vital that they, and the health professionals who serve them, have access to the most current and credible medical information." [5]

Subsequently, the volume of MEDLINE searches has increased remarkably, from 8.5 million a year in 1997 to over 120 million a year later, and nearly 400 million soon thereafter. And, about one-third of the searches were being done by consumers, indicative of the increasing public appetite for health information. 


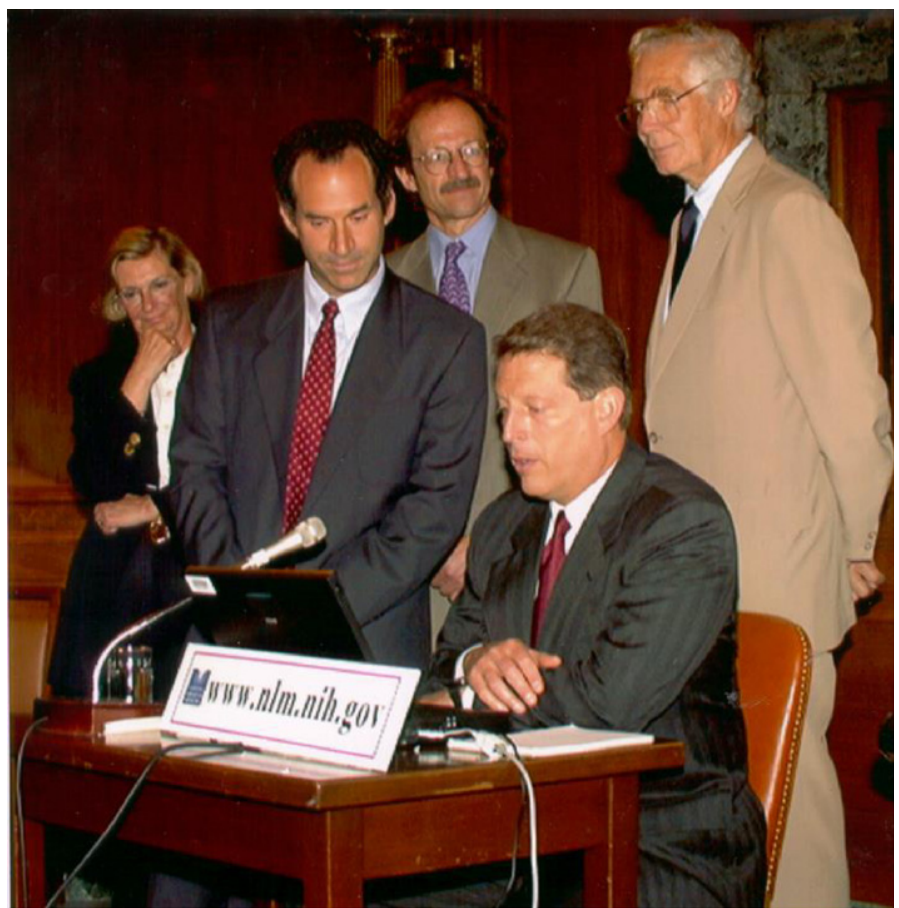

Photo 1. Ceremony on Capitol Hill, June, 26, 1997. On this occasion, Vice President Albert Gore (sitting) introduced free MEDLINE searching via the Internet and demonstrated a new system developed by the library called PubMed, which simplified searching for online medical information by researchers and the public alike. Standing, from left: Suzanne McInerney, David J. Lipman, MD, Director, National Center for Biotechnology Information (NCBI); Harold Varmus, MD, 1989 Nobel Laureate in Physiology or Medicine, and Director, National Institutes of Health, and NLM director Lindberg.

\section{Lindberg champions the rise of NLM consumer-friendly health websites}

Considering this major new group of users of NLM's medical and scientific database MEDLINE, Lindberg commissioned the creation of a new consumer-friendly database called MedlinePlus which debuted on October 22, 1998 [6]. Its mission was to present high-quality, relevant health and wellness information that would be trusted and easy to understand in both English and Spanish. Lindberg wanted to feature health information on surgical procedures, clinical trials, medical professionals and facilities, drugs, and medical terms, among other topics, available to the consumer anytime, anywhere, for free. And Lindberg did not permit advertising on the website, nor did he want the website to promote or endorse any product or company.

By 2018, 277 million users viewed MedlinePlus more than 700 million times. The website now provides information about the symptoms, causes, treatment, and prevention of more than 1,000 diseases.

A new era of timely and trusted online health information for the general public began, stimulated by an NLM initiative to help the public use online health information. In January 2000, Dr. Lindberg announced NLM support for 49 electronic health information projects in 34 states, affecting rural, inner-city, and suburban areas. In announcing the projects, Lindberg noted, "We are supporting the increase in Internet access in a variety of settings, from middle schools serving low income and educationally underserved students to shopping malls and senior centers", he said. "These are imaginative and well-targeted projects that will help us determine how we can best provide millions of Americans who are still not connected to 


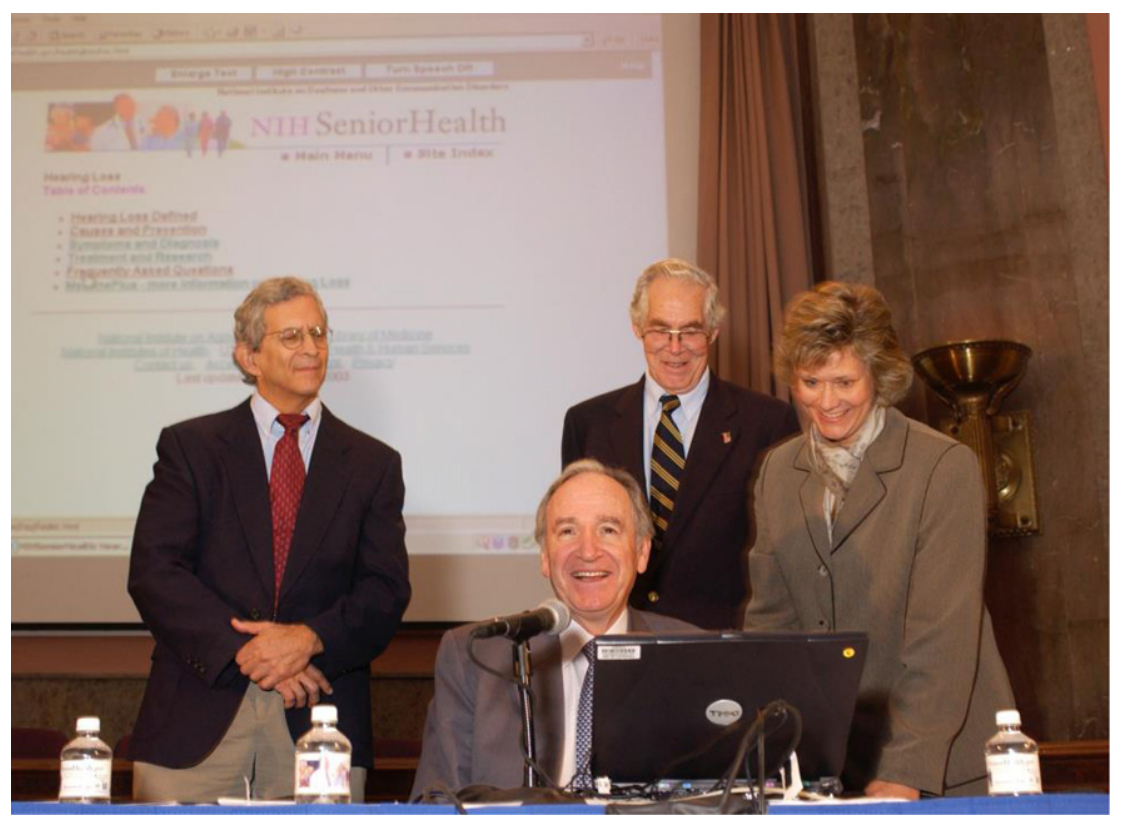

Photo 2. (From left to right). National Institute on Aging Director Richard J. Hodes, M.D., Senator Tom Harkin (D-IA), NLM Director Donald L.B. Lindberg, M.D., and Joyce Backus, Lead Systems Librarian, demonstrate and launch NIH Senior Health in an October 23, 2003, press briefing on Capitol Hill.

the Internet with access to health information. They will stimulate medical libraries, local public libraries, and other organizations to work together to provide new electronic health information services for all citizens in a community" [7].

In addition to Lindberg's efforts to increase consumer access to health information on the Internet, he was encouraging the development of numerous NLM consumer-friendly health websites as well. ClinicalTrials.gov, now the world's largest trial registry and a unique source of summary results data for many trials, was launched soon after in February 2000, providing patients, families, and members of the public with easy access to information about the location of clinical trials, their design and purpose, and criteria for participation [8]. Today, consumers can explore more than 375,000 research studies that are available in all 50 states and in 220 countries worldwide.

In 2003, Lindberg directed the NLM to join the National Institute on Aging to launch NIHSeniorHealth.gov, the first government website designed for older adults that featured authoritative, up-todate information from the NIH, in a format that addressed the cognitive and visual changes that come with aging. The website was launched in an October 23, 2003, press briefing requested by Senator Tom Harkin (D-IA) and co-hosted by NLM Director Lindberg and National Institute on Aging Director Dr. Richard Hodes [9] (See Photo 2). In his opening remarks at the press briefing, Lindberg noted that "the use of the Internet for health information is increasing dramatically", and he added, "but the small type, low contrast, and difficulty in navigating around many sites have been obstacles for seniors. NIHSeniorHealth.gov corrects many of those problems, as well as providing health information that is the best that NIH can offer". Dr. Hodes said, "The way in which people think, learn, and remember, changes with age". He added, "This new web site is based on the latest research on cognition and aging and should prove to be an accessible and understandable way for seniors to find information about their health". 
To develop the website, the NIA and NLM brought together researchers who study cognition, web site designers, and communications experts at the two Institutes to fashion a site that was easy for older adults to read, understand, remember, and navigate.

For example, the site featured large print and short, easy-to-read segments of information repeated in a variety of formats - such as open-captioned videos and short quizzes - to increase the likelihood it would be discovered and remembered. Consistent page layout and prompts help older adults move from one place to another on the site without feeling lost or overwhelmed. Each topic provided general background information, quizzes, frequently asked questions (FAQs), open-captioned video clips, transcripts for the videos, and photos and illustrations with captions. NIHSeniorHealth.gov also had a "talking" function, which allowed users the option of reading the text or listening to it as it is read to them. Finally, in addition to being senior-friendly, the new site was one of the first Internet websites to comply with Section 508 of the Rehabilitation Act of 1973, making it accessible for persons with disabilities.

NIHSeniorHealth.gov was retired on August 1, 2017. Many of the design approaches first developed on NIHSeniorHealth.gov have become best practices for Internet accessibility. These innovations included text resizing, changing color contrast, text-to-voice, "chunked" content, and the use of plain language. Today, innovations in technology have brought us to a point where the pioneering design features of NIHSeniorHealth.gov are now widely available on Web site at the National Institutes of Health and throughout the Internet.

\section{NLM partners with physicians who prescribe MedlinePlus to their patients}

In 2003, Lindberg formed partnerships with physician and health professional organizations (the American College of Physicians, the National Medical Association, the National Alliance for Hispanic Health, etc.) to educate patients about reliable sources of medical information available from the NLM [10]. In partnership with these organizations, NLM launched a campaign called Information Rx, which supplied prescription pads, and other promotional materials to health providers to point their patients to trusted NIH health care information. Press conferences were held in Iowa, Georgia, Florida, and Pennsylvania to alert consumers to the campaign and to increase awareness about other new NLM online health information services. In launching the Information $R x$ project in Georgia, Lindberg said that "as a physician myself, I believe that an informed patient is a 'better' patient". Lindberg added, "Patients armed with good health information tend to take better care of themselves, to take their medications as directed, and to feel that they're in partnership with their doctor, taking an active role in their own health and wellness".

The Information Rx project was a successful concept [11]. NLM found that physicians were eager to point their patients to good sources of health information on the Internet and the information prescription pads provided a good vehicle to do so. Research also indicated that more than $70 \%$ of patients were more likely to go to a website prescribed by their doctor. Ultimately NLM stopped distributing paper prescription pads in favor of experimenting with a more efficient and scalable protocol to connect physician's Electronic Health Record (EHR) systems directly to MedlinePlus, where individual patients could be referred electronically to information relevant to their needs [12].

To comply with a Senate Appropriations Committee request to NLM to increase consumer awareness of NIH funded research findings, Lindberg also found physician offices to be the logical place to fulfill this Senate requirement. Building on the success of NLM's Information Rx project, Lindberg championed the production of NIH's first consumer health magazine, NIH MedlinePlus, to be distributed to the public free of charge in physician offices nationwide. 


\section{NIH MedlinePlus the magazine debuts}

In response to a Senate Appropriations report urging NLM to increase public awareness of NLM services, Lindberg created NIH MedlinePlus - a free bilingual, consumer health magazine in print and online, and NIH's first consumer health magazine. The magazine was developed by Lindberg in consultation with key NLM staff, including the Donald King, M.D., Deputy Director for Research and Development; Kathy Cravedi, Director of NLM's Office of Communications and Public Liaison; Elliot Siegel, Ph.D., Associate Director for NLM's Health Information Programs Development; Peter Reinecke, former Staff Director for Senator Tom Harkin (D-IA) and consultant to NLM's Office of Communications and Public Liaison; Naomi Miller, Manager, Consumer Health Information in the Public Services Division of NLM; and Patricia Carson, Special Assistant to the Director. Early in the development of the magazine, Kathy Cravedi and Peter Reinecke met with John Burklow and Marin Allen, Ph.D., Associate Director and Deputy Associate Director of the NIH Office of Communications and Public Liaison, respectively. Together, they agreed to join the NLM and the Friends of the NLM in the production and distribution of NIH MedlinePlus magazine.

To publicize the availability of this new resource, on September 20, 2006, the National Institutes of Health (NIH), the National Library of Medicine, and the Friends of the National Library of Medicine joined forces at a joint congressional press conference convened in the U.S. Capitol and attended by lawmakers, their staff, and members of the press [13]. Dr. Lindberg was joined by then NIH Director Dr. Elias Zerhouni, who spoke about the new magazine and how it can help to bring good information to the public. Former Senator Tom Harkin (D-IA), the late Congressman Ralph Regula (R-OH), and the late actress Mary Tyler Moore who was featured on the cover of the inaugural issue of the quarterly publication, NIH MedlinePlus, also attended.

As described by Lindberg to the media present at the press briefing, "This new NIH publication was developed to provide Americans with a gold standard of reliable, up-to-date health information, including the results of breakthrough research funded through NIH. It was designed to help Americans take control of their own health and better navigate the health care system". The inaugural issue was sent to doctors' offices so patients could learn about NIH and benefit from the information resulting from NIH-sponsored research (See Photo 3).

As it has since its debut, each issue of NIH MedlinePlus magazine highlighted several major health conditions, giving readers the most up-to-date and authoritative information on prevention, diagnosis, treatment and research findings. It also shone a spotlight on exciting research currently underway on each condition including on-going clinical trials. NIH MedlinePlus armed readers of all ages with the latest information on how to stay healthy for a lifetime. Finally, the magazine profiled some of the most fascinating people - from laboratory scientists to public figures - making a difference in the search for medical breakthroughs. Like its online namesake, MedlinePlus, NIH MedlinePlus contained no commercial advertising, assuring its readers that the information is produced only for the public good. The magazine was a 32-page, full-color, newsstand-quality publication. Each issue contained one or more special sections dedicated to specific health and disease topics. The NLM published four quarterly issues of the magazine each year. Each magazine focuses on the latest research results, clinical trials, and new or updated guidelines from the various NIH Institutes.

In late 2008 and the fall of 2009, NLM and FNLM created and distributed the first and second issues, respectively, of a free bilingual, consumer health magazine, NIH MedlinePlus Salud. NLM partnered on these issues with the National Alliance for Hispanic Health, the nation's oldest and largest network of Hispanic health and human services providers. The dual Spanish/English presentation provided a unique 


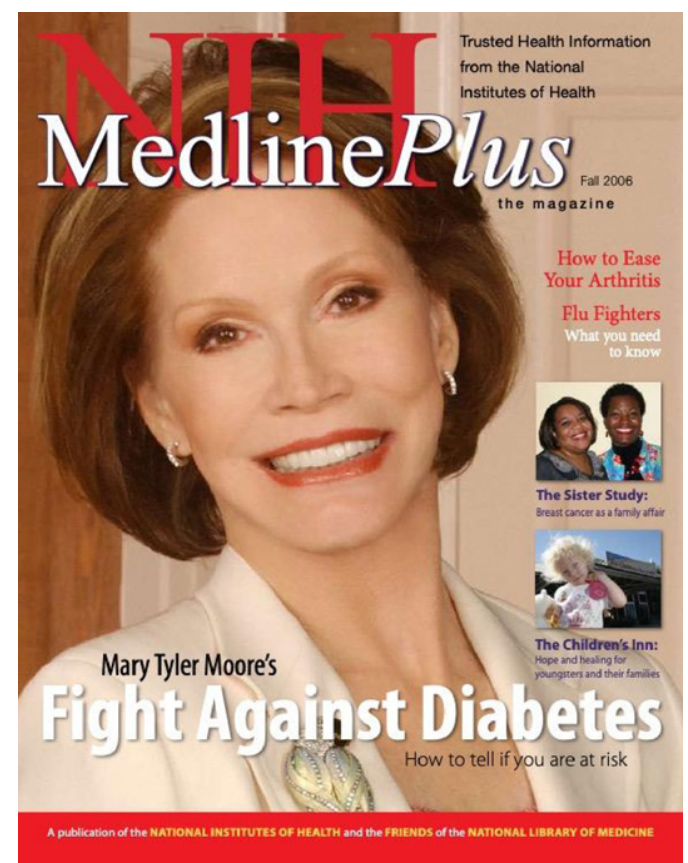

Photo 3. Mary Tyler Moore. Cover image. The NIH MedlinePlus Magazine, Fall, 2006, Friends of the National Library of Medicine.

vehicle to reach Hispanics across a wide demographic. The magazine also showcased the many Hispanicoutreach efforts and research-funded results from the NIH's 27 Institutes and Centers.

All of these efforts stem from a mandate by the U.S. Congress to have NIH and NIH-funded research made clear and available to the American people through accessible, informative, and useful educational vehicles. NIH MedlinePlus and NIH MedlinePlus Salud, in both print and electronic formats, are unique, public-facing information platforms that educate the American people about the NIH's mission, goals, and research results.

To distribute the magazines, NLM secured access to mailing and distribution lists of all U.S. physicians, hospitals, and other healthcare providers. This allowed the magazines to be sent to healthcare providers across the nation for use by their patients in waiting rooms at the point of care. Depending on health conditions featured in individual issues, distribution was customized to reach or target physicians specializing in those conditions to better reach patients interested in obtaining the latest research on their particular health concern.

Distribution totals grew from approximately 40,000 copies for the first issue of NIH MedlinePlus in 2006 to between 250,000 and 500,000 copies for issues that followed. Copies of each issue were sent to physician offices nationwide, to NLM's National Network of Libraries of Medicine, to community health centers across the United States, to the media, to the NIH community, the Congress, and individual subscribers. Topics relating to every NIH center of research have been covered in the published issues of NIH MedlinePlus and NIH MedlinePlus Salud, combined. Single-copy and bulk subscriptions to the two magazines were available upon request.

NIH MedlinePlus magazine has been the recipient of numerous NIH Plain Language Awards, as well as an APEX Award for Publication Excellence. 
Today, the magazine is freely available online - reaching Americans in both their doctor's office as well as in their homes or anywhere worldwide. NLM is continually pioneering the use of social media platforms to promote the magazine and increase public access to NIH cutting-edge research. As an early adopter of social media, the NLM is recognized as a "powerhouse" in reaching and helping consumers find good sources of unbiased health information online.

\section{Conclusion}

Under his leadership, Dr. Lindberg greatly expanded the scope and mission of the National Library of Medicine. Today, NLM and its network of more than 8,000 academic, hospital, and public libraries partner with community-based organizations to bring high-quality information to health professionals and the public-regardless of location, socioeconomic status or access to computers and telecommunications. NLM has entered longstanding and successful partnerships with minority-serving institutions, tribal and community-based organizations, and the public health community. NLM's marvelous exhibitions, discussed in greater detail elsewhere in this book [14], expand NLM's reach with electronic and traveling versions, bringing important issues and scholarship to persons unable to make it through NLM's Bethesda doors.

At his direction, the National Library of Medicine embraced the Internet, enabling the public, health providers, and scientists to gain new or improved access to medical literature via PubMed and PubMed Central; clinical trials and their results via ClinicalTrials.gov; and consumer health information via - MedlinePlus and the NIH MedlinePlus magazine. These advances did not always come easy when public policy and other impediments sometimes needed to be overcome, as detailed elsewhere in this book [15].

In his effort to improve patient outcomes, Dr. Lindberg revolutionized the Library's outreach capabilities and successfully expanded its mission to serve not only health professionals and scientists, but also consumers nationwide.

\section{References}

[1] National Library of Medicine (US). Board of Regents. Improving Health Professionals' Access to Information. [Internet]. U.S Dept. of Health and Human Services, National Institutes of Health, Bethesda, MD, 1989, [cited 2021 July 8]. 28p. Available from: https://collections.nlm.nih.gov/ext/kirtasbse/8912965/PDF/8912965.pdf.

[2] J.E. Backus and E.M. LaCroix, Providing health information for patients, families, and the public. in: Transforming Biomedical Informatics and Health Information Access: Don Lindberg and the U.S. National Library of Medicine, B.L. Humphreys, R.A. Logan, R.A. Miller and E.R. Siegel (eds), IOS Press, Amsterdam, 2021.

[3] National Library of Medicine (US), Report from the board subcommittee on outreach and public information, Minutes of the 112th Meeting of the NLM Board of Regents, May 21-22, 1996. [Internet] [cited 2021 July 16]. P. 3-4. Available from: https://www.nlm.nih.gov/hmd/manuscripts/nlmarchives/bor/May1996.pdf.

[4] National Library of Medicine (US), Internet Grateful Med goes on the world wide web, Press release, NLM Archives, April 8, 1996. [Internet] [cited 2021 July 16]. Available from: https://www.nlm.nih.gov/archive/ 20040831/news/press_releases/igmpr.html.

[5] National Library of Medicine (US), Vice President launches free access to world's largest source of published medical information on world wide web, Press Release, June 26, 1997. [Internet] [cited 2021 July 16]. Available from: https://www.nlm.nih.gov/archive/20050113/news/press_releases/free_medline.html.

[6] National Library of Medicine (US), Public library initiative/new consumer health site, National Library of Medicine to work with public libraries to help consumers find answers to medical questions; new consumer health web site "MedlinePlus" 
launched, Press release, October 22, 1998. [Internet] [cited 2021 July 16]. Available from: https://www.nlm.nih.gov/ archive/20040831/news/press_releases/medplus.html.

[7] National Library of Medicine (US), National Library of Medicine announces initiative to help public use online health information, Press release, January 14, 2000. [Internet] [cited 2021 July 16]. Available from: https://www.nlm.nih.gov/ archive/20040831/news/press_releases/ehip.html.

[8] Science Daily, National Institutes of Health launches "ClinicalTrials.gov." Press release, March 1, 2000. [Internet] [cited 2021 July 16]. Available from: https://www.sciencedaily.com/releases/2000/03/000301074433.htm.

[9] National Library of Medicine (US), NIH launches NIHSeniorHealth.gov; New web site features health information, talking web, easy access for older adults, visually impaired, Press release, October 24, 2003. [Internet] [cited 2021 July 16]. Available from: https://www.nlm.nih.gov/archive/20120510/news/press_releases/nihseniorhealthpr03.html.

[10] National Library of Medicine (US), The health information prescription: Lt. Gov. Mark Taylor, Former HHS Sec. Louis Sullivan, MD join National Library of Medicine and American College of Physicians-American Society of Internal Medicine Foundation to launch patient information program, Press release, March 18, 2003. [Internet] [cited 2021 July 16]. Available from: https://www.nlm.nih.gov/archive/20120510/news/press_releases/GAhealthRX03.html.

[11] E.R. Siegel, R.A. Logan, R.L. Harnsberger, K. Cravedi, J.A. Krause, B. Lyon et al., Information Rx: Evaluation of a new informatics tool for physicians, patients, and libraries, Information Services and Use 26(1) (2006), 1-10. https://lhncbc.nlm.nih.gov/LHC-publications/pubs/InformationRxEvaluationofaNewInformaticsToolforPhysicians PatientsandLibraries.html.

[12] S. Burgess, S. Dennis, S. Lanks, N. Miller and J. Polvin, MedlinePlus Connect: Linking health IT systems to consumer health information, IT Prof. 14(3) (2012), 22-28. https://www.ncbi.nlm.nih.gov/pmc/articles/PMC3469315/.

[13] National Library of Medicine (US), NIH MedlinePlus Magazine debuts, Press release, September 20, 2006. [Internet] [cited 2021 July n16]. Available from: https://wayback.archive-it.org/org-350/20180227224656/https://www.nlm.nih.gov/ news/magazine_debuts06.html.

[14] J. Parascandola, An active contributor: Dr. Lindberg and NLM's historical programs and services. in: Transforming Biomedical Informatics and Health Information Access: Don Lindberg and the U.S. National Library of Medicine, B.L. Humphreys, R.A. Logan, R.A. Miller and E.R. Siegel (eds), IOS Press, Amsterdam, 2021.

[15] K.A. Smith, Free MEDLINE access worldwide. in: Telling Don Lindberg's Story: Leadership, Character, and Teamwork in Transforming Biomedical Informatics and Access to Health Information, B.L. Humphreys, R.A. Logan, R.A. Miller and E.R. Siegel (eds), IOS Press, Amsterdam, 2021. 